\title{
SEAT AIR BLADDER SYSTEM FOR PROTECTING VEHICLE OCCUPANTS FROM SHOCK AND VIBRATION
}

\author{
D.D. Reynolds, Ph.D., University of Nevada, Las Vegas* \\ G. Ladkany, University of Nevada, Las Vegas
}

\section{Introduction}

Landmines are a great threat to military vehicles and their occupants. Mine blasts can completely destroy vehicles and kill all the occupants or disable the vehicle and leave the occupants severely injured. Injuries sustained during a landmine blast come from fragmentation that enters the vehicle through a hull breach, hot gasses expanding through the vehicle, or shock created from the extreme pressure of the landmine blast. $^{2}$ A specially designed air bladder seat cushion can be used to significantly mitigate the high intensity shock experienced by the occupants during a survivable mine.

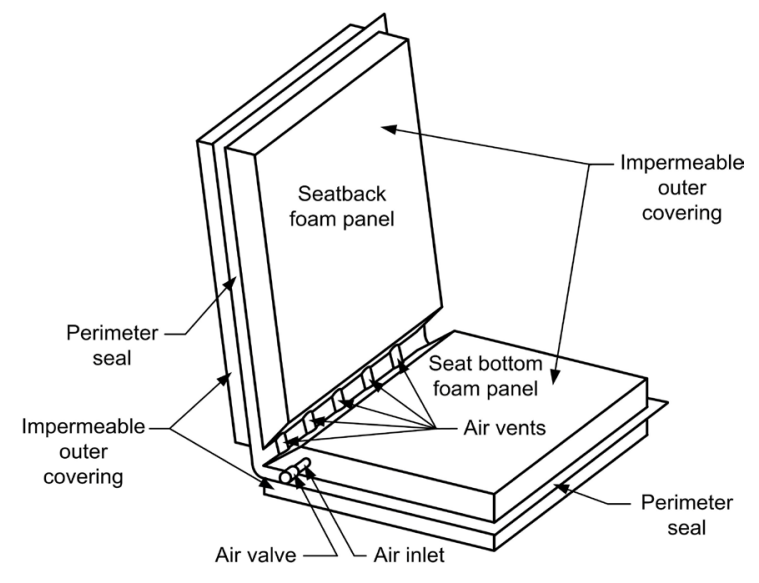

Figure 1

\section{Methods}

Figure 1 shows a schematic representation of the lightweight, foam-filled, inflatable mine blast attenuating seat. It consists of specially designed lightweight foamfiled interconnected seat bottom and seat back air bladders that are supported by a rigid frame. The seat system is to be used in conjunction with a five-point restrain system.

The shock attenuation characteristics of the seat were measured using a Lansmont shock test system drop tower at the U.S. Army Applied Research Laboratory. Drop tower tests were conducted using a Gesac Thor NT anthropodynamic dummy. Two sets of tests were conducted: dummy in a seat frame without the air bladder seat cushion and dummy in a seat frame with the air bladder seat cushion. The seat was dropped from heights that ranged from 5 to $35 \mathrm{in}$. (12.7 to $88.9 \mathrm{~cm})$. The drop tower was set up to create a $5 \mathrm{msec}$ wide shock pulse for each drop height. The parameters that were measured are: acceleration of the seat frame, acceleration between the air bladder seat cushion and the buttock of the dummy, pelvis acceleration of the dummy, and the spine load (force) of the dummy. Parameter measurements were made only in the vertical direction. The dynamic response index (DRI) was calculated from the measured pelvis acceleration.

\section{Results}

Figures 2 through 4 show the results of the drop tower tests. Figure 2 shows the peak pelvis acceleration as a function of the seat frame input acceleration. Figure 3 shows the peak spine load (force) as a function of the seat frame input acceleration. Figure 4 shows the DRI as a function of the seat frame input acceleration. The solid curve in each 
figure shows the results for the seat frame and dummy without the air bladder seat cushion. The dotted curve shows the results for the seat frame and dummy with the air bladder seat cushion.

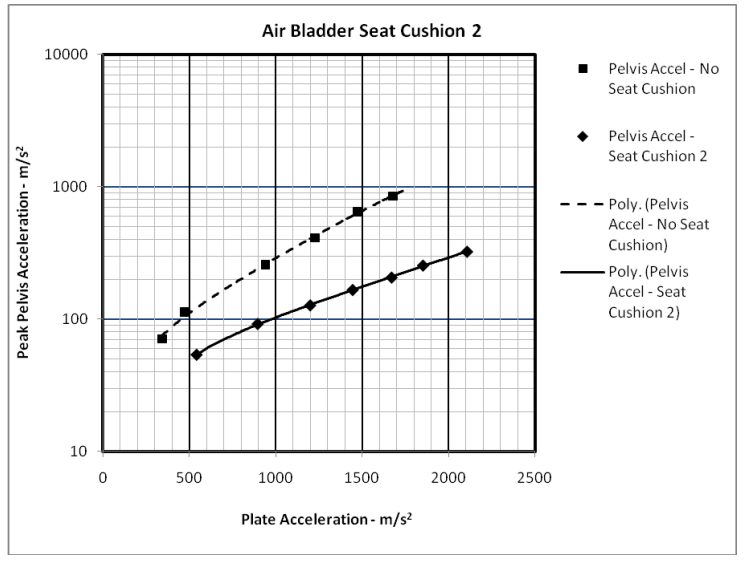

Figure 2

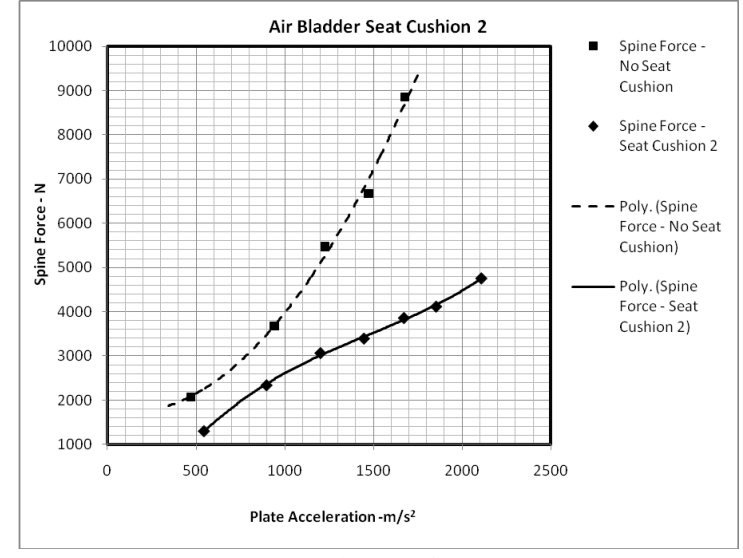

Figure 3

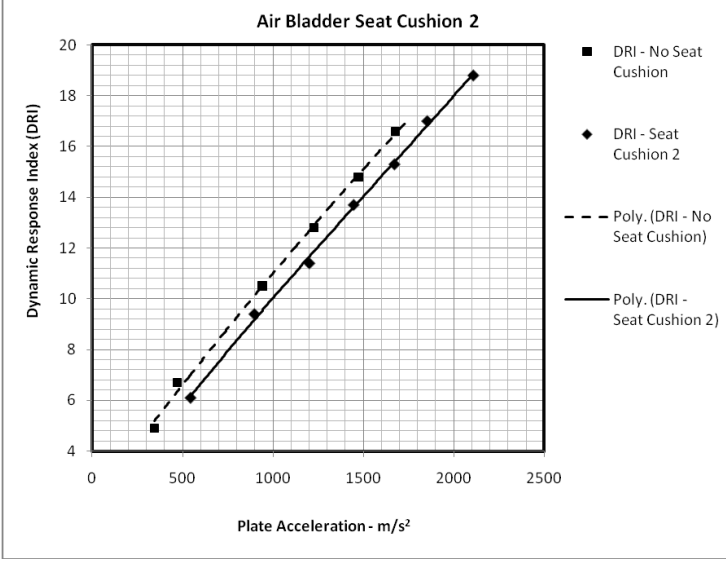

Figure 4

Discussion

The results of the drop tower tests show that the use of the air bladder seat cushion shown in Figure 1 significantly reduced the amplitude of the seat frame shock energy that was transferred to the Thor NT anthropodynamic dummy. At a drop height of 25 in. $(63.5 \mathrm{~cm})$, the peak seat frame acceleration was $1,472 \mathrm{~m} / \mathrm{s}^{2}$. Without the air bladder seat cushion, the dummy's pelvis acceleration was $851 \mathrm{~m} / \mathrm{s}^{2}$, peak spine load (force) was $8,852 \mathrm{~N}$, and DRI was 16.6. With the air bladder seat cushion, the dummy's pelvis acceleration was $236 \mathrm{~m} / \mathrm{s}^{2}$, peak spine load (force) was $4,030 \mathrm{~N}$, and DRI was 15.9 . To minimize the potential for injury, the dummy's pelvis acceleration should be less than 226 $\mathrm{m} / \mathrm{s}^{2}$, spine load (force) should be less than $6,672 \mathrm{~N}$, and DRI should be less than 17.7.

\section{References}

1. Alem, N.M. and Shawn, G.D., January 1996. "Evaluation of an Energy Absorbing Truck Seat for Increased Protection from Landmine Blasts." U.S. Army Aeromedical Research Laboratory, Fort Rucker, Alabama.

2. Lafrance, L.P., 1998, "Mine Blast Protection Systems for Military Support." American Society of Mechanical Engineers, vol. 361 pp. 305-309. 